\title{
Adsorption of Humic Acid onto Jordanian Kaolinite Clay: Effects of Humic Acid Concentration, pH, and Temperature
}

\author{
Khansaa Al-Essa ${ }^{1, *}$, Fawwaz Khalili ${ }^{2}$ \\ ${ }^{1}$ Chemistry Department, Jerash University, Jerash, Jordan \\ ${ }^{2}$ Chemistry Department, University of Jordan, Amman, Jordan
}

\section{Email address:}

k.essa@jpu.edu.jo (K. Al-Essa), khansaa.essa@gmail.com (K. Al-Essa)

${ }^{*}$ Corresponding author

\section{To cite this article:}

Khansaa Al-Essa, Fawwaz Khalili. Adsorption of Humic Acid onto Jordanian Kaolinite Clay: Effects of Humic Acid Concentration, pH, and Temperature. Science Journal of Chemistry. Vol. 6, No. 1, 2018, pp. 1-10. doi: 10.11648/j.sjc.20180601.11

Received: December 7, 2017; Accepted: December 18, 2017; Published: January 11, 2018

\begin{abstract}
Kaolinite clay has low cation exchange capacity and small surface area; it has rarely been used as adsorbent. As well as, green, low cost and efficient adsorbent is desired. Modification of kaolinite is necessary to improve its adsorption capacity. Jordanian kaolinite has been modified by humic acid (HA) through batch adsorption mode. Two types of HA were used; one was commercial (FHA) and the other was natural (KTD). The effect of HA concentration, $\mathrm{pH}$ and temperature of solution were considered. HA adsorption becomes higher at low concentration, decreases with increasing $\mathrm{pH}$, and it increased with solution temperature. Modified Jordanian kaolinite clay was characterized by different techniques: FTIR, TGA, SEM connected to EDS and porosimetry analysis by Gas Adsorption Isotherm and Mercury Porosimetry. The modified kaolinite showed good and strong interaction with HA, enhancement in its surface and charge structure, and increasing in the average pore radius. Therefore, increases in its reactivity and adsorption sites especially towards heavy metal ions. Moreover, FHAkaolinite clay showed better adsorption characteristics than KTD- kaolinite clay.
\end{abstract}

Keywords: Kaolinite, Humic Acid, Batch Adsorption, Adsorption Capacity

\section{Introduction}

Kaolinite is a 1:1 aluminosilicate comprising a tetrahedral silica sheet bonded to an octahedral sheet through the sharing of oxygen atoms between silicon and aluminum atoms in adjacent sheets. The layers are held together by hydrogen bonding of adjacent silica and alumina layers [1]. The tetrahedral sheet carries a small permanent negative charge due to isomorphous substitution of $\mathrm{Si}^{4+}$ by $\mathrm{Al}^{3+}$, leaving a single-negative charge for each substitution [2]. Both the octahedral sheet and the crystal edges have a $\mathrm{pH}$-dependent variable charge caused by protonation and deprotonation of surface hydroxyl (SOH) groups [3]. Thus, the intensive interaction between kaolinite and humic acid (HA) is primarily controlled by the surface acid-base properties. Kaolinite clay has seldom been used as adsorbents because of its low cation exchange capacity (CEC, $3-15 \mathrm{meq} / 100 \mathrm{~g}$ ) and small surface area, which is not more than $20 \mathrm{~m}^{2} \mathrm{~g}^{-1}[4,5]$. Modification of clay minerals can be achieved by either impregnation or grafting of organic/inorganic molecules on its surface [6]. Jordanian HA-kaolinite complex made to improve the adsorption capacity of clay minerals. However, there is dearth of information on the modification of kaolinite clay with HA and the effect of some variables on its adsorption capacity.

HA's are complex aggregates of dark-colored amorphous high molecular weight substances extracted from the natural degradation products of plant and animal residues $[7,8]$. Although considerable work about HA exists, some of them have dealt with HA adsorption on clay minerals, that's because HA solubility increases with increasing $\mathrm{pH}[9,10]$.

Although kaolinite exhibits the least exchangeability among clay minerals, several studies have confirmed the potential of natural kaolinite for the adsorption of metal ions from solution. Moreover, several studies have been done to enhance the adsorption capacity of kaolinite. Saada et al. investigated the influence of organic matter on arsenic retention, they used batch experiments at $\mathrm{pH} 7$ to determine the adsorption of $\mathrm{As}(\mathrm{V})$ on different solids: a crude, purified, 
Ca-exchanged kaolinite and two samples of kaolinite coated with HA's having different nitrogen contents. They first examined the adsorption of each HA onto kaolinite, and then used the HA-kaolinite complexes to study As(V) adsorption. The results clearly show an influence of the HA coating on As(V) adsorption [11].

The effect of HA on the adsorption of the rare earth elements (REEs) on kaolinite and its controlling factors were studied, adsorption experiments were performed at $\mathrm{pH}$ range from 3 to 10 with kaolinite $(1500 \mathrm{mg} / \mathrm{L})$ in a matrix of various concentration of $\mathrm{NaNO}_{3}$ and about $20 \mu \mathrm{g} / \mathrm{L}$ of the total REEs as well as various amounts of HA. The adsorption of HA onto the kaolinite occurred over a wide $\mathrm{pH}$ range and decreases with increasing $\mathrm{pH}$ and HA concentration. The results show that HA has ability to either increase or decrease the adsorption of the REEs onto kaolinite, depending on $\mathrm{pH}$, which may be related to their speciation distribution, interaction of HA with the mineral surface. Furthermore, the light REEs are more adsorbed onto kaolinite in presence of higher concentration of HA, presumably because the increase in HA concentration in the solution enhance stronger complexing of HA with heavy REEs as compare to light REEs [12].

Adsorption of uranyl ions onto kaolinite, HA and composite clay material (both clays and HA) was studied by measuring the system response to clay suspensions (preequilibrated with or without uranyl). Adsorption behavior of selected materials under the frame of batch experiments was tested at high uranyl concentrations $\left(6-1170 \mu \mathrm{g} / \mathrm{mL} ; 2.5 \times 10^{-2}\right.$ to $4.9 \mu \mathrm{M})$, whereas that under flow through continuous stirred reactor experiments was tested at low concentrations $\left(1.00 \times 10^{-4}\right.$ to $\left.1.18 \times 10^{-4} \mathrm{M}\right)$. Both experiments were developed at $\mathrm{pH} 4.5$ and ionic strength $0.2 \mathrm{mM}$. Kaolinite with highly disordered structure adsorbed less uranyl ion $\left(3.86 \times 10^{-6} \mathrm{~mol} / \mathrm{g}\right)$ than well-ordered kaolinite $\left(1.76 \times 10^{-5}\right.$ $\mathrm{mol} / \mathrm{g})[13]$.

Well characterized humic substances (HSs) were adsorbed from aqueous solution onto a Na-kaolin clay. The adsorption affinity and maximum adsorption capacity were correlated with structural features of the HSs. The adsorption affinity was shown to correlate directly with the aromaticity of the HSs and inversely with their polarity, expressed as the $\mathrm{O} / \mathrm{C}$ atomic ratio. Among the HSs studied are the high molecular weight materials enriched with $\mathrm{C}$-and $\mathrm{H}$-substituted aromatics, such as coal and peat HA's. They showed to be the most preferential materials for preparing stable HS-clay complexes [14].

Some studies examined the structural changes of HA after adsorption by clay minerals and determined phenanthrene sorption by humic-clay complexes. Solid-and liquid-state ${ }^{13} \mathrm{C}$ nuclear magnetic resonance (NMR), provided direct evidence for HA fractionation during adsorption on mineral surfaces, that is, aliphatic fractions were preferentially adsorbed by clay minerals while aromatic fractions were left in the solution. The ratio of UV absorbance of HA at 465 and $665 \mathrm{~nm}$, which is related to aromaticity, corroborated with the NMR results. For both montmorillonite and kaolinite, adsorbed HA fractions had higher sorption linearity $(\mathrm{N})$ and affinity $(\mathrm{K}(\mathrm{oc}))$ than the source HA. The $\mathrm{K}(\mathrm{oc})$ of adsorbed HA for the humic-clay complexes could be up to several times higher than that of the source HA. Moreover, for each mineral, the $\mathrm{N}$ values of adsorbed $\mathrm{HA}$ increased with increasing HA loading. It is believed that HA may develop a more condensed structure on mineral surface at lower HA loading level due to the stronger interactions between HA and mineral surface as a result of close contacts [15].

Some results demonstrate that HA's, when they are adsorbed to clay minerals, played an important role in the deposition of polycyclic aromatic hydrocarbons in a soil environment. Terashima et al. studied the distribution behavior of pyrene on HA-kaolin complexes, prepared by adsorbing HA on kaolin, and were investigated by batch experiments. The distribution coefficient $\left(\mathrm{K}_{\mathrm{d}}\right)$ of pyrene on the HA-kaolin complex increased with the fraction of organic carbon adsorbed to the surface of the kaolin. The effects of adsorbed HA's were quantitatively evaluated by calculating the distribution coefficient and affinity constant for pyrene to the adsorbed HA's. These results indicate that the affinity for pyrene is enhanced by the adsorption of HA's to kaolin [16].

Several mechanisms are involved in the adsorption of humic acids by kaolinite, the main ones being: The adsorption affinity increased with decreasing $\mathrm{pH}$, indicating the importance of electrostatic interaction. The hydrophobic interaction and/or H-bonding also played a role. HA adsorption occurred via $\mathrm{OH}$ groups on the edge faces and basal octahedral faces (both positively charged), plus some adsorption at $\mathrm{Si}-\mathrm{O}$ group, at certain $\mathrm{pH}$ values [17].

The adsorption of HA on kaolin particles was studied at various conditions of initial solution $\mathrm{pH}$, ionic strength and solid-to-liquid ratio. The resulting affinity of interactions between HA and kaolin was attributed to the surface coordination of HA in ambient suspensions of mineral particles and the strong electrostatic force at low $\mathrm{pH}$. Addition of inorganic salt can also influence the adsorption behavior by affecting the HA molecular structure, the clay particle zeta potential and so on. Equilibrium data were well fitted by the Freundlich model and implied the occurrence of multilayer adsorption in the process. In addition, the enthalpy dependent of system temperature was $79.17 \mathrm{~kJ} / \mathrm{mol}$, which proved that the mechanism of HA adsorption onto kaolin was comprehensive, including electrostatic attraction, ligand complexation and hydrogen bonding [18].

Few studies have addressed the effect of HA on particle surface characteristics, floc recoverability and fractal structure of alum-kaolin flocs using in situ particle image velocimetry (PIV) and microbalance. Experimental results indicated that the zeta potential of kaolin particle surface after adsorption of HA was related with HA concentration and its acid-base buffering capacity. Adsorption of HA resulted in more negative electrophoresis on the particle surface. Coagulant dosages for particles to form flocs would increase with increasing humic concentration. It was found that the floc size during the steady phase of growth was 
small, while the regrown capability decreased in the presence of HA. The fractal dimensions of alum-kaolin flocs by masssize method based on microbalance would decrease with increasing humic concentration. This study proved that HA had adverse influences on the performance of coagulation process [19].

The sorption of $\mathrm{Cu}$ (II) was investigated on synthetic humus-kaolin complexes. Two groups of humic fractions were compared to investigate the effect of molar mass on the $\mathrm{Cu}$ (II) adsorption capacity. Another approach was to compare the capacities of HA and fulvic acid (FA) to adsorb $\mathrm{Cu}$ (II). The adsorption capacity of fulvic acid on kaolin is smaller than that of HA. The adsorption behavior of fulvic acid on kaolin can be described by a Langmuir-type isotherm. However, the adsorption isotherm of HA on kaolin exhibits non-Langmuir behavior. The results showed the affinity of $\mathrm{Cu}$ (II) on HA was greater than by fulvic acid. However, the affinity of $\mathrm{Cu}(\mathrm{II})$ adsorption by $\mathrm{HA}$ with large molar mass was equal to that by HA with small molar mass. HA-Kaolin complex has a greater $\mathrm{Cu}$ (II) affinity constant that FA-Kaolin complex according to a modified models with either a singlesite or a continuous distribution [20].

The physical and hydrodynamic properties of kaolin flocs including floc size, strength, regrowth, fractal structure and settling velocity were investigated by in situ particle image velocimetry technique at different HA concentration. Jar-test experimental results showed that the adsorbed HA had a significant influence on the coagulation process for alum and ferric chloride. Kaolin flocs formed with the ferric chloride were larger and stronger than those for alum at same HA concentration. Floc strength and regrowth were estimated by strength factor and recovery factor at different HA concentration. It was found that the increased HA concentration had a slight influence on the strength of kaolin flocs and resulted in much worse floc regrowth. In addition, the floc regrowth after breakage depended on the shear history and coagulants under investigation. The changes in fractal structure recorded continuously by in situ particle image velocimetry technique during the growth-breakageregrowth processes provided supporting information that the kaolin flocs exhibited a multilevel structure. It was proved that the increased HA concentration resulted in decrease in mass fractal dimension of kaolin flocs and consequently worse sedimentation performance through free-settling and microbalance techniques [21].

Many researches have been conducted to investigate the effect of adsorption some heavy metals on kaolin in the presence and the absence of HA. The adsorption of chromate on kaolin/HA was studied at various conditions of initial solution $\mathrm{pH}$, ionic strength, water hardness and temperatures. The increased adsorption of chromate in the presence of HA was attributed to the reducing action and complexation of HA. The Langmuir isotherm model fitted the equilibrium data well at low $\mathrm{Cr}(\mathrm{VI})$ concentrations. The saturation amounts for $\mathrm{Cr}(\mathrm{VI})$ adsorbed by kaolin were $0.14,0.16$ and $0.20 \mathrm{mmol} \mathrm{Cr} / \mathrm{g}$ at $283 \mathrm{~K}, 293 \mathrm{~K}$ and $303 \mathrm{~K}$, respectively [22].
The competitive adsorption equilibrium isotherms of $\mathrm{Cu}$ (II) and $\mathrm{Cd}(\mathrm{II})$ on kaolin have been measured at $298 \mathrm{~K}$, in the presence and the absence of HA's. HA's were found to enhance the metal adsorption capacity of mineral surfaces, in particular kaolin. The Freundlich isotherm equation was found to provide an excellent fit to the experimental data. These results were compared with the independent adsorption of both heavy metals [23].

Jordan has huge reserves of kaolinite, spread throughout the country $[24,25,26]$. On the another hand, the gravest environmental challenge that Jordan faces today is the scarcity of water, Jordan has one of the lowest levels of water resources in the world. In addition to that, Water in Jordan has been polluted by different kinds of pollutant like heavy metals.

This study seeks to introduce modified Jordanian kaolinite clay by HA as a new low-cost and more efficient adsorbent; adsorption isotherm of HA on kaolinite clay will be studied at different $(\mathrm{pH})$ and temperatures, to understand its nature, structure, behavior and properties. It is hoped that this modest effort may substitute the deficiency in the literature on the spectroscopic, thermal, adsorption mechanism and adsorption characteristics of clay minerals in Jordan, and to create a new adsorbent that can contribute of the solution of water pollution which is the major problem in the world today.

\section{Experimental}

\subsection{Materials and Chemicals}

All chemicals were obtained from commercial sources as either analytical reagent grade or chemically pure grade and were used as received. The chemicals were purchased from the corresponding companies: sodium hydroxide $\mathrm{NaOH}$ (LOBA), hydrochloric acid; $\mathrm{HCl} 37 \%$ (TEDIA), potassium chloride; $\mathrm{KCl}$ (Puriss), and silver nitrate; $\mathrm{AgNO}_{3}$ (Puriss). Two types of HA were used; one was commercial from Fluka Company (FHA) and the other was natural extracted from King Talal Dam sediments (KTD) [27]. Kaolinite clay was obtained from the Quarry located $45 \mathrm{~km}$ east of Al-Quweira town, Aqaba state, south of Jordan. Its X-ray diffraction analysis is already done by Amer et al. [28].

\subsection{Instrumentation}

Concentrations of HA content were determined using UVVIS Spectrophotometer (Varian Cary100). The instrument was equipped with a quartz cell with a path length of $1 \mathrm{~cm}$. The maximum intensity of the UV light was $0.6 \mathrm{Wm} 2$. Drying of modified kaolinite clay was done by freeze-dryer (ALPHA 1-4). Shaking of samples was done using Clifton Shaker equipped with thermostat and $\mathrm{pH}$ was measured using METROHM $605 \mathrm{pH}$-meter. Characterization the kaolinite clay sample was conducted by FT-IR using Thermo Nicolet NEXUS 670 FT-IR Spectrophotometer, TGA by using NETZCH STA 409 PG/PC Thermal Analyzer and SEM by FEI inspect F50 scanning electron microscope. Surface area 
was measured using (Gemini VII) instrument from Micrometrics, and the porosity of kaolinite clay was measured using Mercury Porosimetry Analyzer instrument (Model: PM-60-13) from Quantachrome Instruments.

\subsection{Methods}

The kaolinite clay samples were crushed and sieved to a particle size $>250 \mu \mathrm{m}$, then the clay fractions were subsequently exchanged with $\mathrm{K}^{+}$ions by washing it four times with $0.5 \mathrm{M} \mathrm{KCl}$ solution. The excess $\mathrm{KCl}$ was removed by repeatedly washing with deionized water until negative $\mathrm{Cl}^{-}$was determined by $\mathrm{AgNO}_{3}$ solution. The clay suspensions were quickly frozen, freeze-dried, and stored in closed containers prior to use [29].

Batch adsorption method was used for the preparation of HA- Jordanian kaolinite complex samples. A 1000 (mg/L) of HA was prepared by dissolving $1.0 \mathrm{~g} \pm 0.1 \mathrm{mg}$ of HA in $1.0 \mathrm{~L}$ of $0.01 \mathrm{M} \mathrm{NaOH}$ solution. The stock solution was diluted with $0.01 \mathrm{M}$ of $\mathrm{NaOH}$ solution for the preparation of more diluted solutions keeping $\mathrm{pH}=11.00$. Batch adsorption was carried out using Pyrex glass vessels. An accurate mass $(0.04 \mathrm{~g} \pm 0.1 \mathrm{mg})$ of kaolinite clay measured to the nearest $0.1 \mathrm{mg}$ was shaken with $20.0 \mathrm{~mL}$ of $(10,30,50,70,90,110$, 130 and $150(\mathrm{mg} / \mathrm{L}))$ solutions of HA for $24 \mathrm{hrs}$ at 25,35 and $45^{\circ} \mathrm{C}$, and $\mathrm{pH}=4.00,5.00$ and 6.00 . The solution was adjusted by $0.10 \mathrm{M} \mathrm{HCl}$ and/or $0.10 \mathrm{M} \mathrm{NaOH}$ to the desired $\mathrm{pH}$. Aliquot of solution was then filtered and analyzed by Ultraviolet-Visible (UV-VIS) spectrophotometer at a certain wavelength for the two kinds of $\mathrm{HA}$ to measure the concentration of free HA. These wavelengths were determined by measuring UV-VIS scan spectra for a blank experiment (without kaolinite) at all $\mathrm{pH}$ values within the range 200-750 nm using Varian Cary 100. The maximum absorbance in visible spectral range was at $\lambda=320 \mathrm{~nm}$ for FHA and $\lambda=215 \mathrm{~nm}$ for KTD-HA. Two kinds of modified kaolinite clay complex were prepared, FHA-kaolinite clay and KTD-kaolinite clay. Calibration curves were determined using standard samples prepared from both HA's at each $\mathrm{pH}$.

\section{Results and Discussion}

\subsection{Adsorption of Humic Acid into Kaolinite Clay}

HA adsorption decreases with increasing $\mathrm{pH}$, (Figures 1 and 2) in a manner typical of "ligand-like adsorption". Both the adsorbent surface and the HA lose their protons as $\mathrm{pH}$ increase and become negatively charged, and consequently repel each other.

On the other hand, because both kaolinite clay and humate are in a hydrogenated form at low $\mathrm{pH}$, the uncharged surface functional groups of the kaolinite surface and HA may attract each other via these protons and the electronegative $\mathrm{O}$ atoms, probably in the form of $\mathrm{H}$ bonds. Thus HA reacts with silanol and aluminol groups of the surface of kaolinite [30]. It can be noticed that $\%$ uptake of FHA on kaolinite clay is higher than KTD-HA, because of the higher $\mathrm{O} / \mathrm{C}$ ratio of the $\mathrm{HA}$ fractions [27].



Figure 1. Percentage (\%) of FHA adsorbed by kaolinite clay at $25^{\circ} \mathrm{C}$ and different $\mathrm{pH}$ versus the initial FHA concentrations.

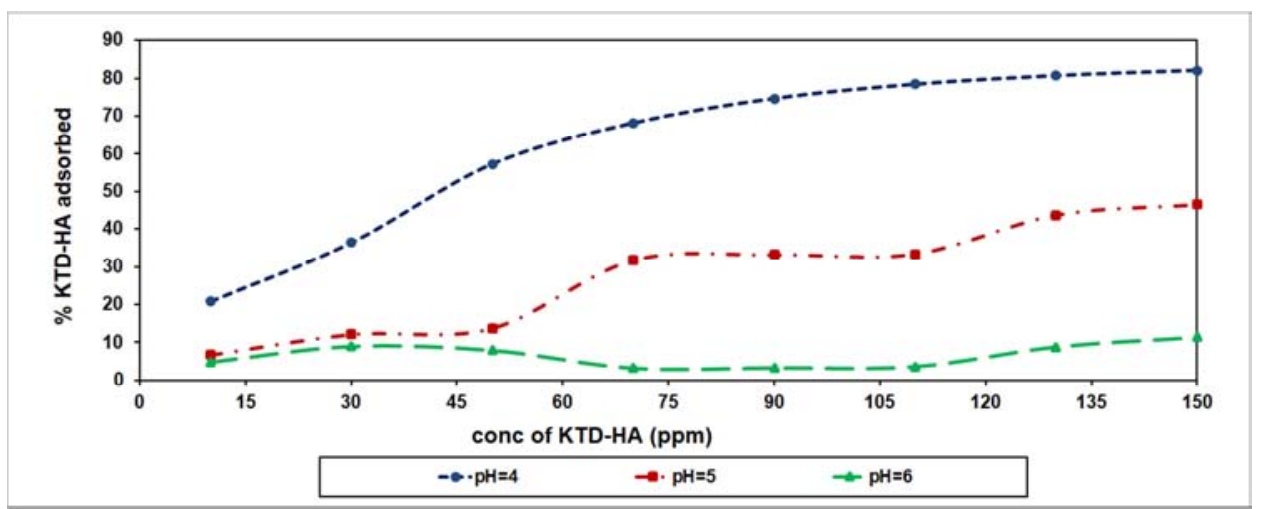

Figure 2. Percentage (\%) of KTD-HA adsorbed by kaolinite clay at $25^{\circ} \mathrm{C}$ and different $\mathrm{pH}$ versus the initial KTD-HA concentrations. 
The \% adsorbed of the two HA's on kaolinite clay as a function of temperature is shown in Figures 3 and 4 . It can be seen that the adsorption of KTD-HA increased with the increase of the solution temperature more than FHA. 93\% and $80 \%$ were the calculated uptake of FHA and KTD-HA on kaolinite clay, respectively.

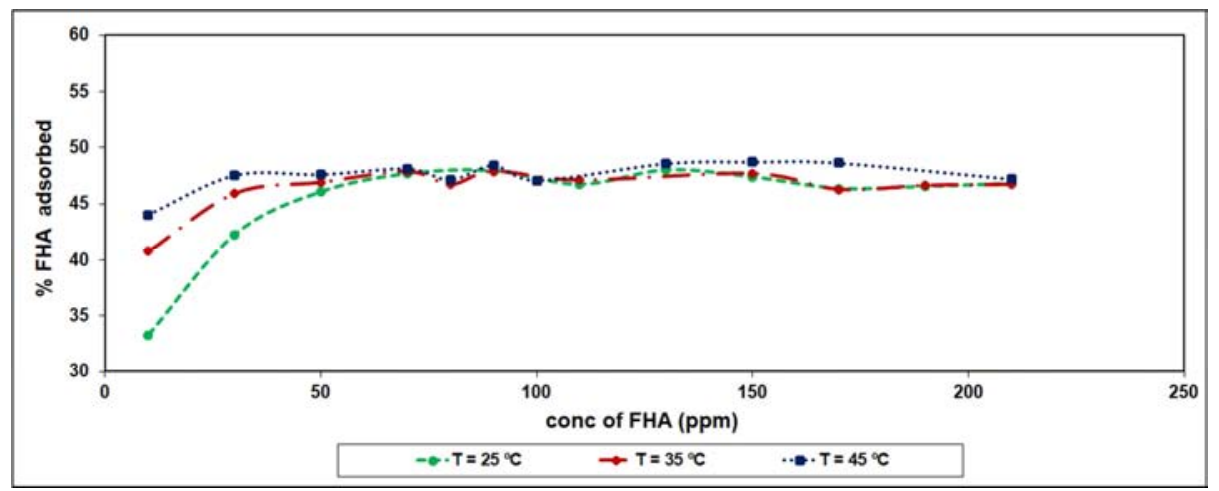

Figure 3. \% adsorbed of FHA on kaolinite clay versus initial FHA concentrations at different temperatures and at $p H=4$.

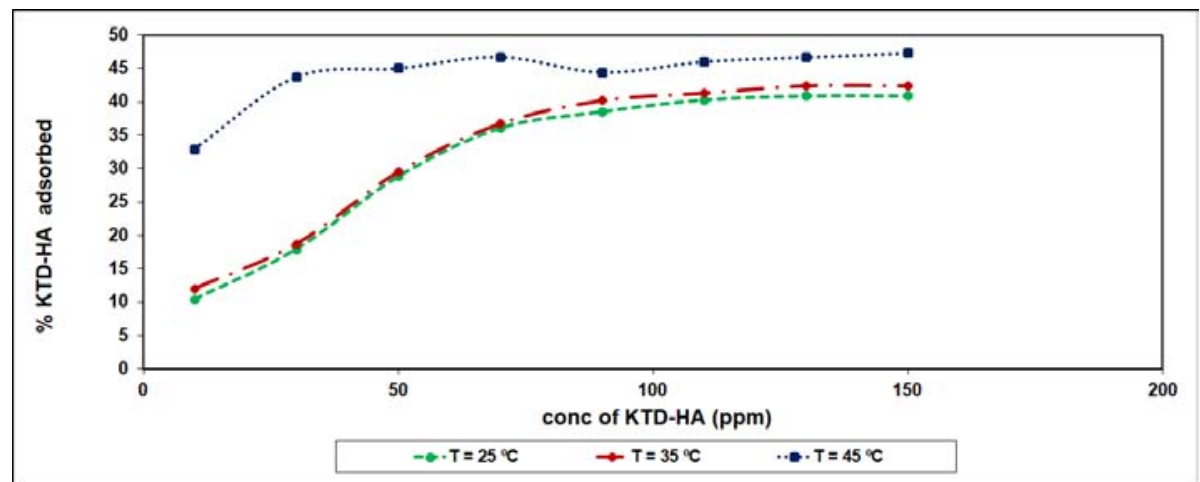

Figure 4. \% adsorbed of KTD-HA on kaolinite clay versus initial KTD-HA concentrations at different temperatures and at $p H=4$.

Some studies were done in our laboratory on the Jordanian clay. Adsorption isotherms of HA onto Jordanian bentonite were studied at different $\mathrm{pH}(3.0-6.0)$ and temperature values. The Langmuir monolayer adsorption capacity was found to be $53 \mathrm{mg} \mathrm{HA} / \mathrm{g}$ raw bentonite at $\mathrm{pH}=3.0$ and $25^{\circ} \mathrm{C}$. Treatment of raw bentonite with $\mathrm{NaCl}, \mathrm{CH}_{3} \mathrm{COOH}$ and $\mathrm{HCOOH}$ does not affect adsorptivity $\left(\mathrm{q}_{\mathrm{m}}\right.$ and $\left.\mathrm{K}_{\mathrm{L}}\right)$ of $\mathrm{HA}$ on bentonite, while treatment with $\mathrm{HCl}$ causes great decrease in adsorptivity. The adsorptivity of HA on bentonite was found to be inversely proportional to the increase in $\mathrm{pH}$ because of the increase in repulsion between HA and bentonite [31].

\subsection{Characterization of Modified Kaolinite Clay}

\subsubsection{Fourier Transform Infrared (FT-IR) Spectroscopy}

According to Table 1, the IR data showed the following characteristic peaks, in the range of the $\mathrm{OH}$ stretching vibrations, the band experimentally observed at $3620 \mathrm{~cm}^{-1}$ corresponds to the inner $\mathrm{OH}$ stretching. The one observed at $3695 \mathrm{~cm}^{-1}$ corresponds to the stretching vibration modes of 'inner surface hydroxyls' that are located at the surface of the octahedral sheets opposite to the tetrahedral oxygen's of the adjacent kaolinite layer [32].

The band at $3485 \mathrm{~cm}^{-1}$ refers to $\mathrm{OH}$ stretching of water, while the bands in the ranges of 1100 to $1000 \mathrm{~cm}^{-1}$ are referred to $\mathrm{Si}-\mathrm{O}$ stretching vibrations at 1102 and $1091 \mathrm{~cm}^{-1}$. While the band at $1002 \mathrm{~cm}^{-1}$ is rather caused by $\mathrm{Si}-\mathrm{O}-\mathrm{Si}$ and
$\mathrm{Si}-\mathrm{O}-\mathrm{Al}$ lattice vibrations. The $\mathrm{OH}$ bending vibration at 912 $\mathrm{cm}^{-1}$ is referred to the 'inner $\mathrm{OH}$ bending'. Further, bands at 794 and $692 \mathrm{~cm}^{-1}$ can be largely attributed to different $\mathrm{Si}-\mathrm{O}$ vibration [33]. The band at $536 \mathrm{~cm}^{-1}$ refers to $\mathrm{Al}-\mathrm{O}-\mathrm{Si}$ deformation, but $\mathrm{Si}-\mathrm{O}-\mathrm{Si}$ deformations occur at $469 \mathrm{~cm}^{-1}$ and $428 \mathrm{~cm}^{-1}$. No major peaks where observed for HA in the modified kaolinite due to its small amount.

Table 1. FT-IR position $\left(\mathrm{cm}^{-1}\right)$ for kaolinite [34].

\begin{tabular}{lll}
\hline $\begin{array}{l}\text { Position } \\
\left(\mathbf{c m}^{-1}\right)\end{array}$ & Theoretical Assignment & $\begin{array}{l}\text { Experimental } \\
\text { Assignment }\end{array}$ \\
\hline 3695 & OH stretching of inner-surface hydroxyl groups & Yes \\
3669 & OH stretching of inner-surface hydroxyl groups & No \\
3651 & OH stretching of inner-surface hydroxyl groups & No \\
3620 & OH stretching of inner hydroxyl groups & Yes \\
3485 & OH stretching of water & Yes \\
1625 & OH deformation of water & Yes \\
1102 & perpendicular Si-O stretching & Yes \\
1091 & In-plane Si-O stretching & Yes \\
1002 & In-plane Si-O stretching & Yes \\
938 & OH deformation of inner-surface hydroxyl group & No \\
913 & OH deformation of inner hydroxyl groups & Yes \\
795 & Si-O & Yes \\
755 & Si-O, perpendicular & No \\
697 & Si-O, perpendicular & Yes \\
602 & Si-O & No \\
507 & Al-O-Si deformation & Yes \\
469 & Si-O-Si deformation & Yes \\
428 & Si-O deformation & Yes \\
\hline
\end{tabular}




\subsubsection{Thermal Properties}

The thermal stability of the Jordanian kaolinite clay was investigated by thermogravimetric analysis (TGA) under dry nitrogen atmosphere. TGA has been used widely in the study of thermal reactions of clay minerals. These reactions in Figure 5 include dehydration of adsorbed water at $\mathrm{T}<150^{\circ} \mathrm{C}$, dehydroxylation (evolution of water from hydroxyls belonging to the clay skeleton) followed by the transformation of the kaolinite to a meta-phase and recrystallization of the meta-phase into a crystalline phase (in the range of $400-650^{\circ} \mathrm{C}$ ).

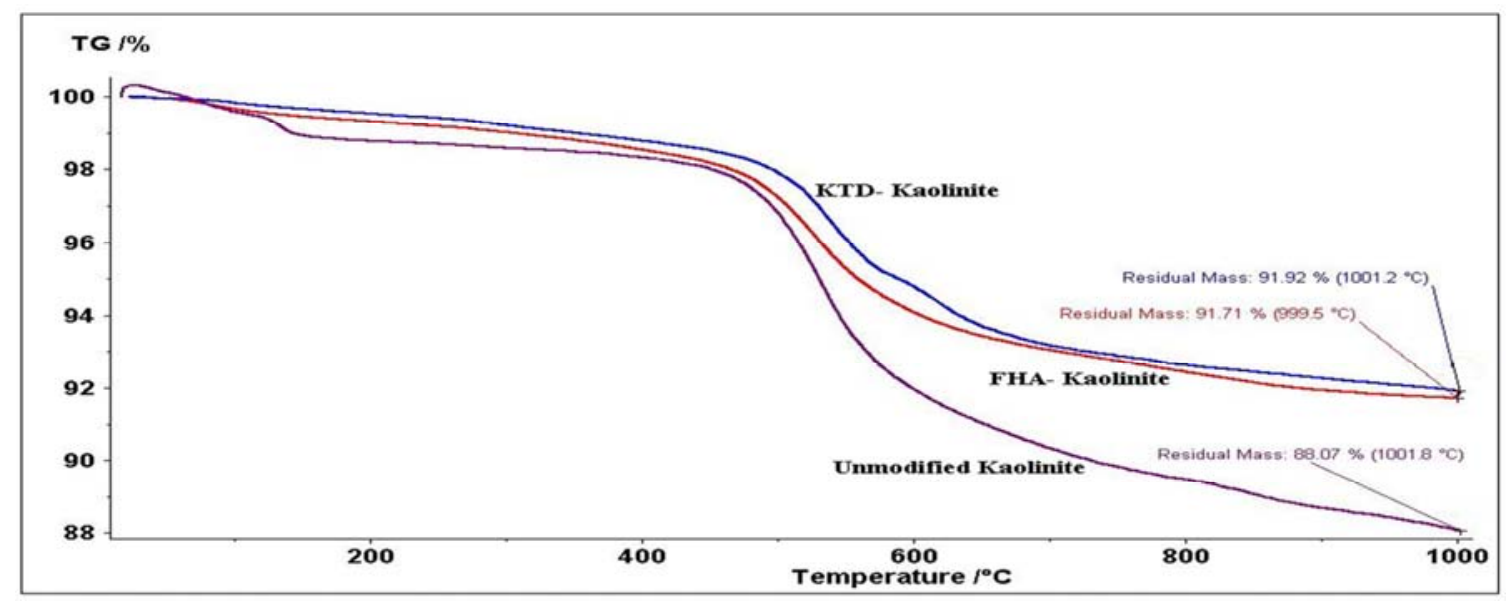

Figure 5. TGA thermogram of unmodified clay and both modified Jordanian kaolinite clay.

The thermogram showed sharp drop for unmodified Jordanian kaolinite clay, after about $500^{\circ} \mathrm{C}$, while a less sharp drop for modified kaolinite clay, this may indicate there is a slight increase in thermal stability of modified kaolinite clay. While the residual mass percentage at $1000^{\circ} \mathrm{C}$ equal to $88.07 \%, 91.71 \%$, and 91.92 , for unmodified kaolinite clay, FHA - kaolinite clay and KTD, respectively. This could indicate more thermal stability of modified kaolinite clay, which is calculated of 3.64 for FHA- kaolinite clay and 3.85 for KTD- kaolinite. That is due to the presence of HA and to the loss of the crystalline water that decreases with modification. The thermogram showed a small drop at $\mathrm{T}<150^{\circ} \mathrm{C}$ for unmodified kaolinite clay, which represent the release of the absorbed water in pores and on the surfaces.
While it is, absent in modified kaolinite clay, which mean that kaolinite adsorbed HA with release of water molecules. This is a good indicator of the presence HA in the modified kaolinite clay.

Even that HA is an easily thermodegradable molecule, is completely degraded between 400 to $600^{\circ} \mathrm{C}[35,36]$, but its adsorption leads to a little increase in the thermal stability of modified Jordanian kaolinite clay.

\subsubsection{Scanning Electron Microscope (SEM)}

\section{a. Unmodified kaolinite clay}

SEM observed the surface topography of unmodified Jordanian kaolinite clay before adsorption of HA, and the results are shown in Figure 6.

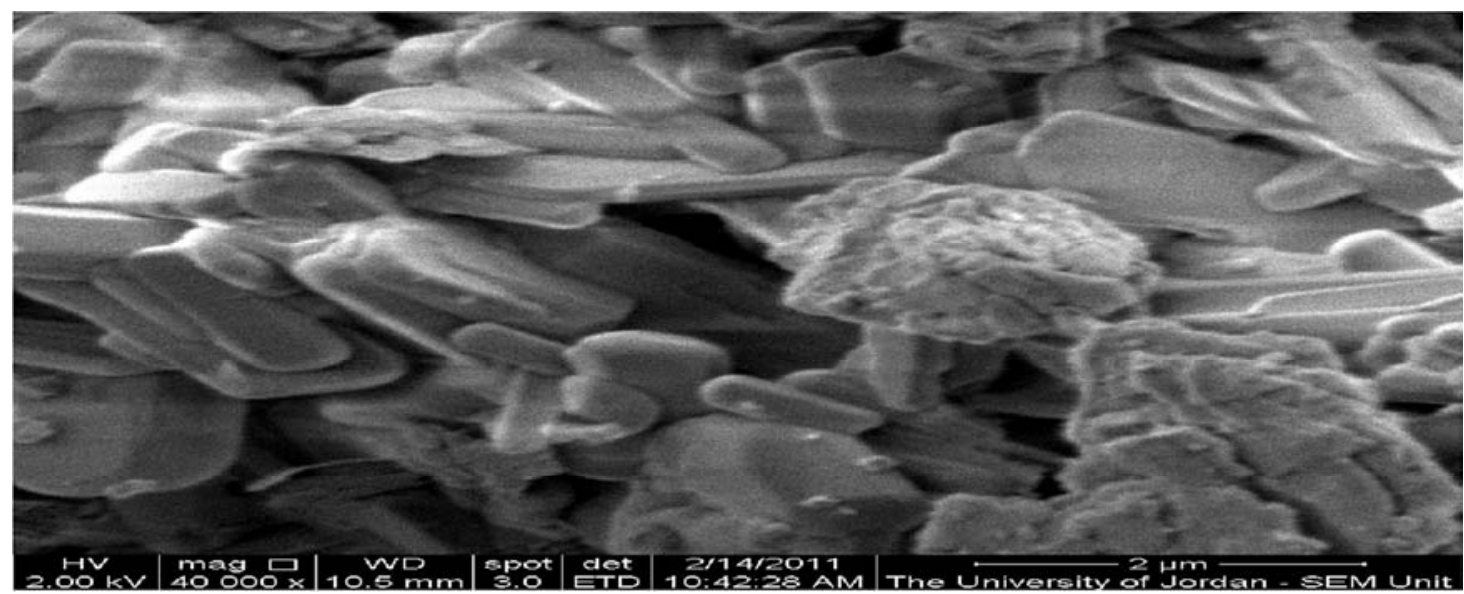

Figure 6. SEM micrographs for unmodified Jordanian kaolinite clay with magnification 40000x.

The clay fractions that are $>250 \mu \mathrm{m}$ of kaolinite clay consists of pseudohexagonal crystals. The crystals typically are thin and flexible plates. As shown, there are also distributed pores and a plate-like structure in the photo- micrographs, with high crystallinity and a high degree of ordering.

b. Modified kaolinite clay 




(a)



(b)

Figure 7. SEM for FHA-kaolinite clay prepared by batch adsorption method with magnification (a) 28313x, (b) 50000x. (93\% uptake of FHA on kaolinite clay was determined by (UV-VIS) spectrophotometer).

With reference to Figure 7, it can observe the changes after the adsorption of the HA to the kaolinite clay. SEM shows that aggregation of HA particles occurred mainly as elongated layers and bundles of fibers, forming a relatively open structure. On the other hand, the fibers tend to mesh into a network to yield a sponge-like and sheet with homogeneous grains distribution.

The adsorption efficiency of humic substances is related to the pore size of the adsorbent. According to literature reports, 50-200 $\mu \mathrm{m}$ pore size of adsorbent is suitable for the adsorption of humic substances [37]. The pore size of the kaolinite clay used in this study was determined by Mercury
Porosimetry Analyzer to be between 4.3 to $224.2 \mu \mathrm{m}$ and was effective as an adsorbent for the adsorption of the humic substances.

c. Energy dispersive X-ray spectroscopy (EDS) of unmodified and modified kaolinite clay

The EDS for unmodified and modified Jordanian kaolinite clay were done. The EDS results are shown in Figures 6 and 7. The EDS give the type and weight percent of each element present in the selected point of sample in the SEM micrographs. The percentage of each element after normalization is presented in Table 2 .

Table 2. Normalized \% mass of elements in unmodified and both modified Jordanian kaolinite clay.

\begin{tabular}{llll}
\hline Element & $\begin{array}{l}\text { \% mass of elements in unmodified } \\
\text { kaolinite clay }\end{array}$ & $\begin{array}{l}\text { \% mass of elements in FHA-kaolinite } \\
\text { clay }\end{array}$ & $\begin{array}{l}\text { \% mass of elements in KTD-kaolinite } \\
\text { clay }\end{array}$ \\
\hline $\mathrm{O}$ & 70.75 & 68.00 & 62.50 \\
$\mathrm{Al}$ & 10.10 & 5.00 & 7.50 \\
$\mathrm{Si}$ & 19.15 & 20.50 & 22.50 \\
$\mathrm{C}$ & - & 3.50 & 2.50 \\
$\mathrm{~N}$ & - & 3.00 & 5.00 \\
\hline
\end{tabular}

According to the definition of kaolinite, it consists of $\mathrm{Si}$, $\mathrm{Al}$ and $\mathrm{O}$. Same results were obtained from EDS analysis.

A clear difference between EDS analysis of unmodified kaolinite clay and the others which are modified by HA's. Such as the appearance of new elements $\mathrm{C}$ and $\mathrm{N}$ due to the $\mathrm{HA}$, this resulted in the decrease in the percentage of $\mathrm{O}$ and Al.

The exact composition of HA varies from one source to another. Two types of HA were used; commercial from Fluka company (FHA) and natural extracted from King Talal Dam (KTD). Percentage (\%) of oxygen in KTD-kaolinite clay is less than FHA-kaolinite clay, while the percentage (\%) of nitrogen is higher; it may be due to degradation of dead organic matter in the dam.

\subsubsection{Surface Area and Porosity of Unmodified and Modified Kaolinite Clay}

Pore sizes and porosity are usually quoted in the terms: micropore (pore diameter range $<2.0 \mathrm{~nm}$ ), mesopore (pore diameter range $2.0-50 \mathrm{~nm}$ ), and macropore (pore diameter range $>50 \mathrm{~nm}$ ). The most common techniques for porosimetry analysis are Gas Adsorption Isotherm (for the micro and meso pore range) and Mercury Porosimetry (for the meso and macro pore range) [38].

a. Gas Adsorption Isotherms

Probably the most widely used and studied technique for surface area determination is that of gas adsorption. The amount of gas adsorbed by a solid as a function of pressure is determined either gravimetrically or volumetrically and the surface area calculated from the adsorption isotherm models such as Langmuir [39]. A common practice in determining the surface area of porous materials is using the adsorption of nitrogen gas. This inert gas interacts weakly with the solid, and then measuring the amount of adsorbed gas that covers the entire surface is feasible.

The most basic theory in adsorption is the Langmuir theory. This theory describes the monolayer surface 
adsorption on an ideal surface. Equating the rates of adsorption and desorption (evaporation), and obtaining the Langmuir isotherm are potential [40]. Surface area of unmodified and both modified kaolinite clay was measured using (Gemini VII) instrument according to Langmuir surface area method which is based on the isothermal adsorption of nitrogen.

$\mathrm{N}_{2}$ gas can only capture or fill the micro and meso pores only; Gas Adsorption Isotherm used for small pore diameter analysis. According to Table 3, the unmodified kaolinite clay has large number of pores in the range of micro and meso size, "small size pores". This is a very important reason for the modification of kaolinite clay by HA. The modified kaolinite clay has smaller number of pores with small range diameter, due to HA adsorption.

\section{b. Mercury Porosimetry}

Mercury Porosimetry [41] is suitable for the meso and macro pore range; it is used for large pore diameter analysis. Table 3, summarizes the measured total porosity of the clays using this analyzer instrument.

Table 3. Langmuir calculated surface area and total porosity [\%] of unmodified and both modified Jordanian kaolinite clay.

\begin{tabular}{lll}
\hline Type of clay & $\begin{array}{l}\text { Surface area } \\
\left(\mathbf{m}^{2} / \mathbf{g}\right)\end{array}$ & $\begin{array}{l}\text { Total porosity } \\
{[\%]}\end{array}$ \\
\hline Unmodified kaolinite clay & 33.5 & 3.4 \\
FHA- kaolinite clay & 12.8 & 5.6 \\
KTD- kaolinite clay & 15.8 & 4.2 \\
\hline
\end{tabular}

Let us summarize briefly these findings. The surface area is the highest for unmodified kaolinite, Initial increase of the HA content leads to rather rapid decrease of the surface area of the modified kaolinite samples. However further increase of the HA content drastically reduces the amount of adsorbed $\mathrm{N}_{2}$ gas. Thus, with increase of concentration the distribution of organic particles on the kaolinite surface changes. At the first stage 'new' parts of kaolinite surface are covered, but next the HA builds 'thicker' structure and is deposited on already covered parts of the surface.

It can be concluded that the subsequent increase of the HA content has slight effect on the average pore radius. Obviously, the bonding of humic substances by mineral components of clay can change their organization and the structure. At low HA concentration, it can be expected that the adsorption of HA on kaolinite particles leading to flocculation of this mineral $[42,43]$. With increase of the HA amount formation of steric (e.g., honeycomb), bigger floccules or aggregates and creation of new pores occur. Still further increase of HA content may lead to blocking the pores which have been already formed during flocculation. Thus, the changes in the porosity may be interpreted as the result of interplay between formation of new pores (flocculation and aggregation) and blocking the pores caused by adsorption. These changes concern wider pores macro and mezopores; eventual changes in very fine pores are out of mercury intrusion detection range. Same results were obtained by Sokołowska and Sokołowski, they found that the changes of the surface properties of the samples of kaolin amended with different amounts of HA are not proportional to the amount of HA added. The surface fractal dimension is the highest for untreated kaolin, attains a minimum for samples with a small amount of HA added and smoothly increases to a constant value [44].

Small amount of HA deposited on kaolinite surface blocks the narrowest pores, in which $\mathrm{N}_{2}$ gas is strongly adsorbed. Addition of HA causes the pore size distribution becomes narrower, but further changes of porosity with HA are small. These pores cannot be detected by mercury porosimetry measurements. The values evaluated from mercury intrusion measurements are lower than those calculated from $\mathrm{N}_{2}$ gas adsorption data. Also, in effect of HA deposition, wider pores, accessible to mercury become narrower. Higher values of surface area, determined from $\mathrm{N}_{2}$ gas measurements than the values obtained from mercury intrusion data indicate that finer pores, which can be penetrated by $\mathrm{N}_{2}$ gas, are more geometrically heterogeneous than wider pores accessible to mercury.

These results approved what SEM of modified kaolinite clay appeared, Figures 6 and 7. Moreover, FHA- kaolinite clay has large numbers of large pores diameter than KTDkaolinite clay. This means that kaolinite clay has been absorbed FHA more than KTD-HA. (93\% uptake of FHA on kaolinite clay was determined by (UV-VIS) spectrophotometer). This is supported by results obtained by EDS analysis, Table 2, where the percentage (\%) of oxygen in KTD-kaolinite clay is less than FHA-kaolinite clay.

Modified kaolinite clay by HA is better for adsorption heavy metal ions, especially in the hydrated form, than unmodified one. On the other hand, FHA- kaolinite clay is better for adsorption of heavy metal ions than KTDkaolinite clay. Therefore, a greater density of adsorption sites e.g. carboxyl and phenolic hydroxyl sites in FHA, enhance the adsorption of metal ions.

Finally, it's worth to mention that this prepared HAkaolinite clay complex is examined to adsorb some heavy metal ions from aqueous solution, the obtained results were published recently [45].

\section{Conclusions}

Modification of kaolinite clay with $\mathrm{HA}$ in order to in enhance its adsorption capacity towards metal ions. HA adsorption decreases with increasing $\mathrm{pH}$, and decreasing the temperature of solution. Several characterization methods support that kaolinite can adsorb HA. TGA thermogram showed more thermal stability of modified kaolinite clay over the unmodified one. The total porosity of modified kaolinite is increased. Therefore, increases in its reactivity and adsorption behavior.

\section{References}

[1] Omara S, Turky G, Ghoneim A, Thünemann A, Abdel Rehim M, Schönhals A. Hyperbranched poly(amidoamine)/kaolinite nanocomposites: Structure and charge carrier dynamics. Polymer. 2017;121:64-74. 
[2] Restrepo D, Griebel C, Giesler K, et al. Mechanochemically enhanced synthesis of isomorphously substituted kaolinites. Applied Clay Science. 2011; 52: 386-391.

[3] Schulze D. Dixon J. Weed S. Minerals in Soil Environment. second edition. Soil Science Society of America. Madison, USA; 1989. p.1.

[4] Lv G, Stockwell C, Niles J, Minegar S, Li Z, Jiang W. Uptake and retention of amitriptyline by kaolinite. Journal of Colloid and Interface Science. 2013; 411:198-203.

[5] Zhu X, Zhu Z, Lei X, Yan C. Defects in structure as the sources of the surface charges of kaolinite. Applied Clay Science. 2016; 124-125:127-136.

[6] Loganathan P, Vigneswaran S, Kandasamy J. Enhanced removal of nitrate from water using surface modification of adsorbents - A review. Journal of Environmental Management. 2013; 131: 363-374.

[7] Chen S, Huang S, Chiang $\mathrm{P}$, et al. Influence of chemical compositions and molecular weights of humic acids on $\mathrm{Cr}(\mathrm{VI})$ photo-reduction. Journal of Hazardous Materials. 2011;197:337-344.

[8] Stevenson F. J. Humus Chemistry. Genesis, Composition, Reactions. First edition. New York: John Wiley and Sons; 1982. P. 443.

[9] Klučáková M, Dissociation properties and behavior of active humic fractions dissolved in aqueous systems. Reactive and Functional Polymers. 2016;109:9-14.

[10] Hizal J, Apak R. Modeling of cadmium(II) adsorption on kaolinite-based clays in the absence and presence of humic acid. Applied Clay Science. 2006; 32:232-244.

[11] Saada A, Breeze D, Crouzet C, Cornu S, Baranger P. Adsorption of arsenic(V) on kaolinite and on kaolinite-humic acid complexes Role of humic acid nitrogen groups. Chemosphere. 2003; 51:757-763.

[12] Wan Y, Liu C. The effect of humic acid on the adsorption of REEs on kaolin. Colloids and Surfaces A: Physicochemical Engineering Aspects. 2006; 290:112-117.

[13] Camposa B, Carrillo J, Algarra M, et al. Adsorption of uranyl ions on kaolinite, montmorillonite, humic acid and composite clay material. Applied Clay Science. 2013; 85:53-63.

[14] G. Balcke, N. Kulikova, S. Hesse, F. Kopinke, I. Perminova, and F. Frimme, Adsorption of Humic Substances onto Kaolin Clay Related to Their Structural Features. Soil Science Society of America Journal. 2002; 66:1805-1812.

[15] Wang K, Xing B. Structural and sorption characteristics of adsorbed humic acid on clay minerals. Journal of Environmental Quality. 2005; 34: 342-349.

[16] Terashima M, Tanaka S, Fukushima M. Distribution Behavior of Pyrene to Adsorbed Humic Acids on Kaolin. Journal of Environmental Quality. 2003; 32:591-598.

[17] Chen H, Koopal L, Xiong J, Avena M, Tan W. Mechanisms of soil humic acid adsorption onto montmorillonite and kaolinite. Journal of Colloid and Interface Science. 2017; 504:457-467.

[18] Qinyan Y, Ying L, Baoyu G. Impact factors and thermodynamic characteristics of aquatic humic acid loaded onto kaolin. Colloids and Surfaces B: Biointerfaces. 2009; 72:241-247.
[19] Zhong R, Zhang X, Xiao F, Li X. Effects of humic acid on recoverability and fractal structure of alum-kaolin flocs. Journal of Environmental Sciences. 2011; 23:731-737.

[20] Huang C, Yang Y. Adsorption characteristics of $\mathrm{Cu}(\mathrm{II})$ on humus-kaolin complexes. Water Research. 1995; 29:24552460 .

[21] Zhong R, Zhang X, Xiao F, Li X, Cai Z. Effects of humic acid on physical and hydrodynamic properties of kaolin flocs by particle image velocimetry. Water Research. 2011; 45:3981-3990.

[22] Li Y, Yue Q, Gao B. Effect of humic acid on the $\mathrm{Cr}(\mathrm{VI})$ adsorption onto Kaolin. Applied Clay Science. 2010;48: 481484.

[23] Arias M, Barral M, Mejuto J. Enhancement of copper and cadmium adsorption on kaolin by the presence of humic acids. Chemosphere. 2002; 48:1081-1088.

[24] Yager T. The mineral industries of Jordan, Lebanon, and Syria. U.S. Geological Survey Minerals Yearbook; 2000. P. $38.1-38.8$.

[25] Khoury H, El-Sakka W. Mineralogical and industrial characterization of the Batn El-Ghoul clay deposits, southern Jordan. Applied Clay Science. 1986; 1:321-331.

[26] Taib M. 2011 Minerals Yearbook, The Mineral Industry of Jordan, U.S. Geological Survey; 2013. 51.1-51.7.

[27] Khalili F. Humic and Fulvic Acids from Several Locations in Jordan. Dirasat. 1987; 14:151-162.

[28] Amer M, Khalili F, Awwad A. Adsorption of lead, zinc and cadmium ions on polyphosphate-modified kaolinite clay. Journal of Environmental Chemistry and Ecotoxicology. 2010; 2:001-008.

[29] Li H, Sheng G, Teppen B, Johnston C, Boyd S. Sorption and desorption of pesticides by clay minerals and humic acid-clay complexes. Soil Science Society of America Journal. 2003; 67:122-131.

[30] Hizal J, Apak R. Modeling of copper(II) and lead(II) adsorption on kaolinite-based clay minerals individually and in the presence of humic acid. Journal of Colloid and Interface Science. 2006; 295:1-13.

[31] Salman M, El-Eswed B, Khalili F. Adsorption of humic acid on bentonite. Applied Clay Science. 2007; 38:51-56.

[32] Bish D. Rietveld refinement of the kaolinite structure at $1.5 \mathrm{~K}$. Clays and Clay Minerals. 1993; 41:738-744.

[33] Reyes C, Williams C, Alarcón O. Synthesis of zeolite LTA from thermally treated kaolinite. Antioquia. 2010; 53:30-41.

[34] Madejova J, Komadel P. Baseline studies of the Clay Minerals Society Source Clays: Infrared methods. Clays and Clay Minerals. 2001; 49:410-432.

[35] Santos A, Botero W, Bellin I, et al. Interaction between humic substances and metallic ions: a selectivity study of humic substances and their possible therapeutic application. Journal of the Brazilian Chemical Society. 2007;18: 824-830.

[36] Rosa J, Knickerb H, López-Capelc E, Manningc D, González-Perezd J, González-Vilad F. Direct detection of black carbon in soils by Py-GC/MS, Carbon-13 NMR spectroscopy and thermogravimetric techniques. Soil Science Society of America Journal. 2007; 72:258-267. 
[37] Summers R, Roberts P. Activated carbon adsorption of humic substances. Journal of Colloid and Interface Science. 1988; 122:367-381.

[38] Meyer K, Klobes P. Comparison between different presentations of pore size distribution in porous materials. Fresenius Journal of Analytical Chemistry.1999; 363:174-178.

[39] Sudibandriyo M. A simple technique for surface area determination through supercritical $\mathrm{CO} 2$ adsorption. Journal of Makara Technology. 2010; 14:1-6.

[40] Largitte L, Pasquier R. A review of the kinetics adsorption models and their application to the adsorption of lead by an activated carbon. Chemical Engineering Research and Design. 2016; 109:495-504.

[41] Webb P. An Introduction to The Physical Characterization of Materials by Mercury Intrusion Porosimetry with Emphasis On Reduction and Presentation of Experimental Data. Micromeritics Instrument Corporation. Norcross, Georgia; 2001. P. 1-23.
[42] Jekel M. The stabilization of dispersed mineral particles by adsorption of humic substances. Water Research. 1986; 20:1543-1554.

[43] Kretzchmar R, Robage W, Weed S. Flocculation of kaolinite solid clays: effect of humic substances and iron oxides. Soil Science Society of America Journal. 1993; 57:1277-1283.

[44] Sokołowska Z, Sokołowski S. Influence of humic acid on surface fractal dimension of kaolin: analysis of mercury porosimetry and water vapour adsorption data. Geoderma. 1999;88:233-249.

[45] Al-Essa K, Khalili F. Sorption of $\mathrm{Pb}(\mathrm{II})$ Ions by Kaolinite Modified with Humic Acids. Journal of Environmental Science and Engineering A. 2016; 5:416-431. 